Vulnerabilidades urbanas en los países andinos

(Bolivia, Ecuador, Perú)

\title{
Descubrimiento de un entierro del Arcaico temprano en el sur del Perú
}

Tania Delabarde, Danièle Lavallée, Aldo Bolaños y Michèle Julien

\section{(2) OpenEdition}

Journals

Edición electrónica

URL: http://journals.openedition.org/bifea/2550

DOI: $10.4000 /$ bifea. 2550

ISSN: 2076-5827

\section{Editor}

Institut Français d'Études Andines

Edición impresa

Fecha de publicación: 1 diciembre 2009

Paginación: 939-946

ISSN: 0303-7495

\section{Referencia electrónica}

Tania Delabarde, Danièle Lavallée, Aldo Bolaños y Michèle Julien, « Descubrimiento de un entierro del Arcaico temprano en el sur del Perú », Bulletin de l'Institut français d'études andines [En línea], 38 (3) | 2009, Publicado el 01 junio 2010, consultado el 10 diciembre 2020. URL : http:// journals.openedition.org/bifea/2550 ; DOI : https://doi.org/10.4000/bifea.2550

\section{(c) (i) $\odot$}

Les contenus du Bulletin de l'Institut français d'études andines sont mis à disposition selon les termes de la licence Creative Commons Attribution - Pas d'Utilisation Commerciale - Pas de Modification 4.0 International. 


\section{AvanCES DE INVESTIGACIÓN}




\title{
Descubrimiento de un entierro del Arcaico temprano en el sur del Perú
}

\author{
Tania Delabarde* \\ Danièle Lavallée** \\ Aldo Bolaños ${ }^{* * *}$ \\ Michèle Julien ${ }^{* * * *}$
}

Al finalizar la temporada de excavación 2007 en el campamento de Quebrada de Los Burros (QLB), el levantamiento de una capa de valvas del molusco Perumytilus purpuratus (chorito de playa) en el nivel N7, que corresponde a la ocupación más antigua del sitio, reveló una interrupción de los depósitos en el metro M8 (ángulo suroeste de la excavación). La extensión de las conchas dejaba lugar a una zona de arena estéril de 5/6 cm de grosor, cubriendo una estructura elíptica conformada por grandes bloques de piedra (7 eran visibles) (fig. 1). En el espacio interior de la estructura — de aproximadamente $75 \mathrm{~cm}$ de largo y $50 \mathrm{~cm}$ de ancho-, un decapado liviano puso al descubierto, al nivel de la base de las piedras, elementos muy fragilizados de un esqueleto humano: la parte posterior del cráneo, la epífisis articular superior de un húmero, una clavícula y el borde de una escápula. Estos restos, de una disposición anatómica aparentemente correcta, parecían corresponder a la mitad superior de un cuerpo. Fuera del óvalo de piedras, se distinguía un conjunto de falanges (por ahora, difíciles de identificar).

Considerando la importancia de este descubrimiento (lastimosamente ocurrido el último día de la temporada), decidimos interrumpir la exploración, proteger

Instituto Francés de Estudios Andinos (IFEA, UMIFRE 17, CNRS-MAEE, Quito). E-mail: tania. delabarde@gmail.com

** UMR 8096, CNRS (Nanterre, Francia). Investigadora asociada del IFEA (UMIFRE 17, CNRSMAEE).E-mail: daniele.lavallee@wanadoo.fr

*** Universidad Nacional Mayor de San Marcos (Lima, Perú). E-mail: aldofernando@yahoo.com

**** UMR 7041, CNRS (Nanterre, Francia). Investigadora asociada del IFEA (UMIFRE 17, CNRSMAEE).E-mail: michele.julien@mae.u-paris10.fr 
cuidadosamente los restos mediante una cobertura de arena de casi $2 \mathrm{~m}$ de grosor y postergar su explotación para una próxima temporada, la cual se desarrolló del 9 al 12 de noviembre de 2009.

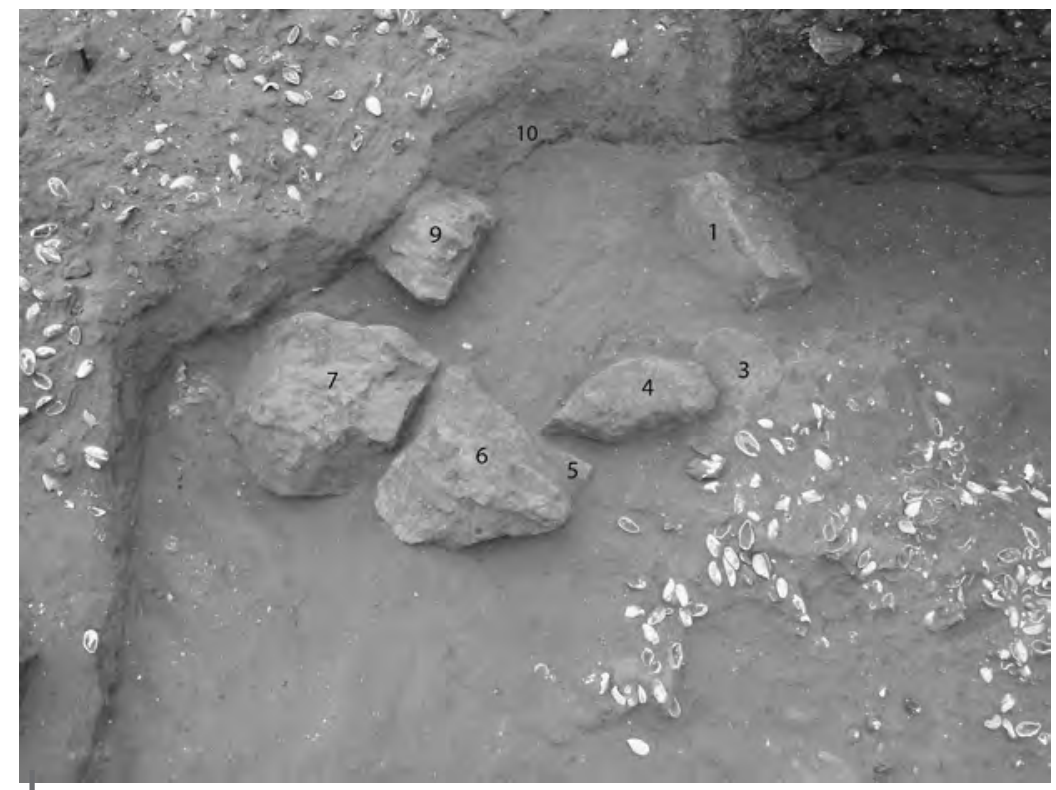

Figura 1 - QLB - Estado de la sepultura encontrada en el metro M8 al final de la excavación del nivel N7 del campamento

Solo se ven aquí 7 bloques de piedra, los bloques 2, 8 y 10 estando todavía cubiertos por la arena. Arriba a la derecha, el perfil L/M 7-8 en límite del área de excavación Foto: Proyecto Arqueológico Perú-Sur

\section{CONTEXTO CRONOLÓGICO}

Recordaremos primero el contexto arqueocronológico. El campamento arcaico de QLB estuvo conformado por instalaciones de pescadores y recolectores de moluscos que, durante el Holoceno temprano y medio, siguieron a lo largo de más de dos mil quinientos años en una pequeña quebrada litoral del departamento de Tacna (prov. Tacna, distr. Sama), a 2 km de la línea de costa y a $170 \mathrm{msnm}$. Seis niveles sucesivos de ocupación (N7 a N2, del más antiguo al más reciente) fueron descubiertos en diez temporadas de excavación por área sobre una superficie continua de $150 \mathrm{~m}^{2}$, en el marco del Proyecto Arqueológico PERU-SUR' (Lavallée, 2003; Lavallée et al., 1999a; 1999b; Lavallée \& Julien, 2001; 2005; 2008). Las ocupaciones se suceden entre $8675 \pm 40$ y $6050 \pm 80$ a.P. (edades convencionales, sobre carbón) es decir, en edades calibradas², entre 9604 y 6900 cal. a.P.

1 El proyecto está financiado por la Comisión de Investigaciones Arqueológicas del Ministerio de Relaciones Exteriores (MAEE) y por el CNRS de Francia.

2 Se refiere a la curva de calibración «Fairbanks 0107» (Fairbanks et al., 2005: 1781-1796). 
Para el nivel N7, donde se sitúa el entierro, tenemos dos fechados ${ }^{14} \mathrm{C}, 8675 \pm 40$ a.P. (SacA 7589) y $8460 \pm 80$ a.P. (GifA-102446), es decir, 9473 y 9604 cal. a.P.

El sedimento que embala los restos óseos es el mismo que el del nivel N7 en conjunto — una arena fina muy suelta de color beige anaranjado—-, muy diferente al sedimento del nivel superior N6, de color grisáceo por la presencia de cenizas. La observación de los mosaicos fotográficos verticales de los niveles N6 y N5 no ha revelado ninguna perturbación de los depósitos en los metros L-M 7-8. De la misma manera, el perfil vertical en el límite del área de excavación (M/N 7-8) no mostraba indicios de haber sido cavado desde los niveles superiores. Todo indica, entonces, que el entierro se remonta hacia el final de la ocupación de N7, siendo, de todas formas, anterior a la ocupación de N6.

\section{DESCRIPCIÓN GENERAL DEL ESQUELETO}

La excavación de la tumba se realizó de acuerdo al protocolo de recuperación de muestras genéticas. Empleamos vestimentas estériles, guantes y máscaras quirúrgicas para evitar la contaminación y permitir la extracción del ADN antiguo. Las muestras fueron enviadas, 48 horas después, al laboratorio de Antropología Molecular de Estrasburgo (Francia), donde hoy están siendo procesadas.

Los restos articulados de un individuo adulto completo se registraron en la fosa en posición hiperflexionada. El difunto reposa en decúbito lateral izquierdo con la cabeza al sur y los pies al norte (figs. 2-3). El cráneo aparece en la cara lateral derecha. Se pudo observar algunas manchas negras al nivel del parietal izquierdo y una muestra fue tomada para determinar si se trata de un proceso tafonómico (descomposición) o un tratamiento funerario específico (coloración). El brazo derecho aparece en cara posterior con el antebrazo hiperflexionado y la mano en pronación al nivel de la mandíbula. El brazo izquierdo se encontró al nivel de la columna dorsal con el antebrazo flexionado en un ángulo de $45^{\circ}$ y la mano izquierda aparece en cara palmar a la altura del hueso coxal izquierdo. Los miembros inferiores están hiperflexionados con los talones ubicados al nivel de la cintura pélvica y las rodillas a la altura del antebrazo derecho. Ningún elemento óseo se encontró fuera del volumen del cuerpo, a pesar de la presencia de un sedimento muy suelto. Además, el difunto se encontró completo y articulado; lo que sugiere la presencia inicial de un elemento envolviendo el cuerpo que ha permitido la preservación de la posición hiperflexionada y ha impedido la caída de los elementos óseos durante el proceso de descomposición.

\section{1. Arreglo funerario}

Hemos reconstruido el proceso de inhumación: después de haber liberado un espacio en el metro M8, descartando las conchas más allá en la pendiente, se cavó una fosa en la arena suelta. Es imposible determinar sus dimensiones exactas por la homogeneidad de la matriz pero su profundidad máxima se encuentra entre 50 y $60 \mathrm{~cm}$ por debajo del nivel N7. Luego se depositó el cuerpo envuelto. 
Tania Delabarde, Danièle Lavallée, Aldo Bolaños, Michèle Julien

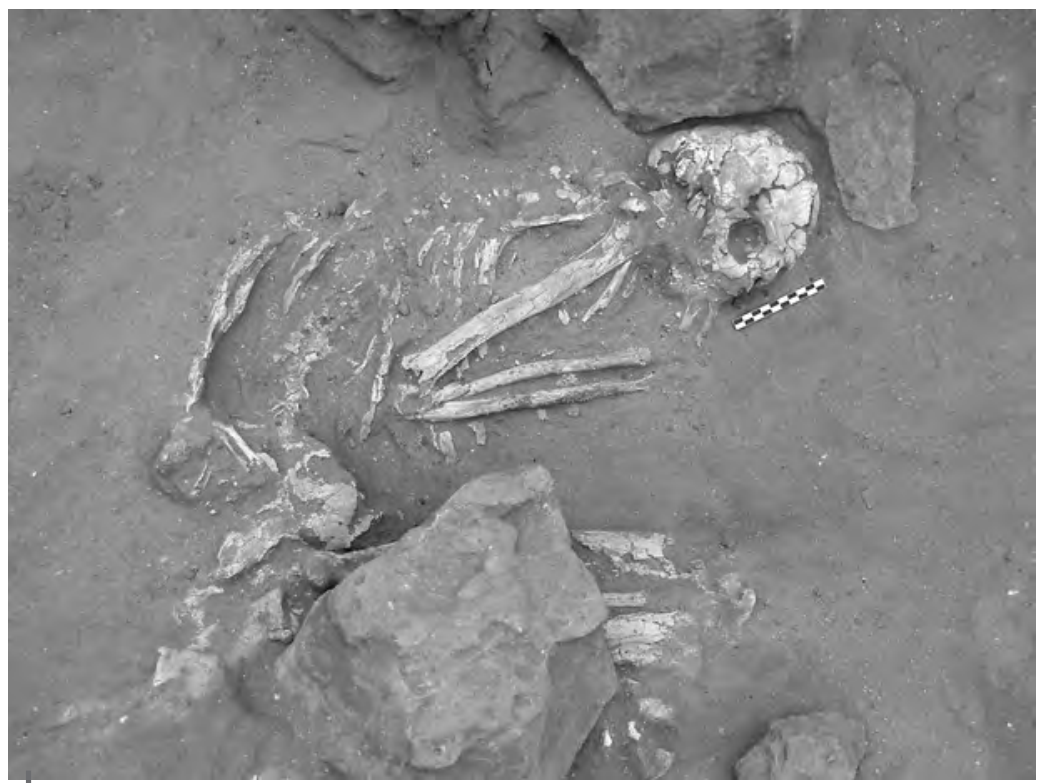

Figura 2 - QLB, entierro N7-M8. Vista general del difunto

Se trata de un adulto joven completo y articulado, reposando en posición hiperflexionada. La mandíbula es ausente porque fue retirada apenas su excavación para la toma de muestras biológicas (extracción del ADN)

Foto: Proyecto Arqueológico Perú-Sur

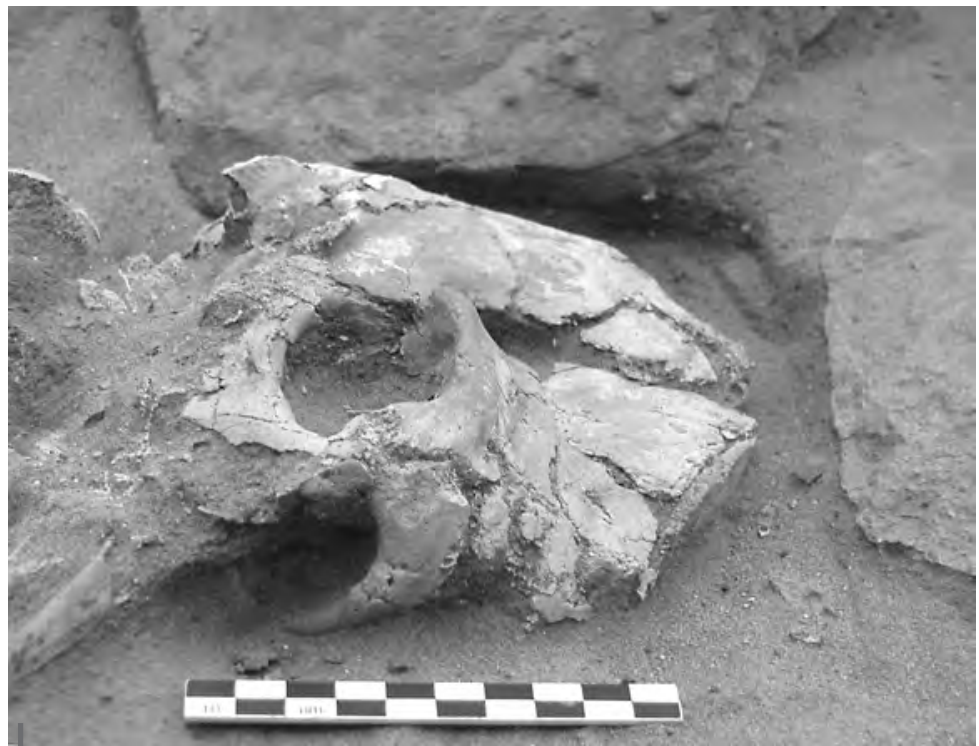

Figura 3 - QLB entierro N7-M8. Detalle del cráneo del difunto

Foto: Proyecto Arqueológico Perú-Sur 
Primero se colocan dos piedras atrás de la cabeza: un bloque de $30 \mathrm{~cm}$ de ancho (bloque 1), cuya cara plana se orienta hacia el cuerpo, y una laja de $20 \mathrm{~cm}$ de ancho (bloque 2) dispuesta verticalmente. Ocho piedras conformando un medio círculo de $80 \mathrm{~cm}$ de diámetro máximo se encuentran dispuestas encima del paquete funerario. Tres se colocan hacia la parte anterior del cuerpo, una (bloque 3) cubre en parte el bloque 2 cerca de la cabeza, dos están dispuestas a lo largo del brazo derecho flexionado (bloque 4) y del tórax (bloque 5). Luego, dos piedras más voluminosas fueron depositadas: la primera (bloque 6) apoyada en parte sobre el bloque 5 encima de las rodillas; la segunda (bloque 7), sobre los fémures y tibias. Al final se cierra la estructura con tres últimas piedras menores (bloques 8, 9, 10) que se colocan sobre la pelvis y la columna, cubriendo también parcialmente el brazo izquierdo. Solo los pies quedan en el exterior de la estructura, lo que sugiere que el depósito de las piedras no tenía por objetivo rodear el cuerpo sino más bien señalar el lugar del entierro.

No había ningún ajuar funerario alrededor del cuerpo pero, sobre los bloques 1 y 2 (más cercanos a la cabeza del difunto), se observaron huellas de colorantes negro y rojo. Además, una concha de loco (Concholepas concholepas) fue encontrada debajo del bloque 4, sin que se pueda concluir su depósito intencional.

El pésimo estado de conservación del esqueleto (muy fragmentado y frágil) hacía imposible su recuperación sin correr el riesgo de destruirlo. La aplicación de consolidante tipo Paraloid fue descartada para no impedir la adecuada observación de los huesos y la aplicación de otros tipos de estudios; entonces, se decidió por dejar los restos en el lugar en que fueron encontrados. Se cubrió el cuerpo con una primera capa de arena cernida y limpia y luego una segunda, procedente del mismo desmonte de excavación, cernida durante las temporadas anteriores del proyecto, quedando así totalmente cubierta.

\section{2. Determinación del perfil biológico}

El estudio antropológico se desarrolló in situ. La determinación del sexo se realizó en base al dimorfismo sexual del cráneo, considerando que el estado de preservación de la cintura pélvica no permitió ninguna observación. El proceso mastoideo derecho (el mejor preservado) está muy desarrollado (criterio=4). La glabela está muy marcada (criterio $=4$ ) y el borde superior orbital es también importante $($ criterio $=3,5)$. La eminencia mandibular está muy prominente $($ criterio=4). El estudio de los caracteres craneales previamente expuestos comprueba que se trata de un individuo de sexo masculino.

La edad, correspondiente a la de un individuo adulto joven, se calculó en base a la erupción dental (de los terceros molares) y al desarrollo óseo y dental. Todos los dientes superiores e inferiores del lado derecho están presentes, en cambio ninguna observación se pudo hacer del deteriorado lado izquierdo. El estado general de la dentadura es normal de acuerdo a la edad del individuo, con poco cálculo dental y un desgaste mediano. Ninguna lesión «cariosa» se registró en las 
piezas dentales presentes. Una lesión de forma ovalar $(1,8 \times 1,2 \mathrm{~cm})$ se ubica en la porción izquierda de la sutura frontonasal, presentando una destrucción del tejido óseo adyacente y una «hipervascularización» de la zona. Se trata de una lesión de tipo hiperostosis porotica (fig. 4). Se registraron también lesiones bilaterales del tipo criba orbitalia al nivel de ambos techos de las órbitas. Este conjunto de lesiones pueden estar relacionadas, considerando la localización de las lesiones y la naturaleza porotica de las mismas; sin embargo el estado de preservación del esqueleto impide el estudio de todos los elementos óseos para determinar un diagnóstico infeccioso o de carencia alimentaria. Cabe mencionar la ausencia hipoplásica del esmalte en los dientes, generalmente relacionada con un problema anémico. El estudio de las características craneales está en proceso así como el análisis de una posible lesión del conducto auditivo, en relación con una práctica repetida del buceo (Legent, 2003).

Estos datos están actualmente procesados y comparados con los estudios antropológicos de sitios contemporáneos, esperando obtener más información sobre las afinidades biológicas de este individuo. Esperemos también que la extracción del ADN sea exitosa para definir su perfil filogenético, lo que sería una fuente extraordinaria de datos acerca del origen del poblamiento de la zona.

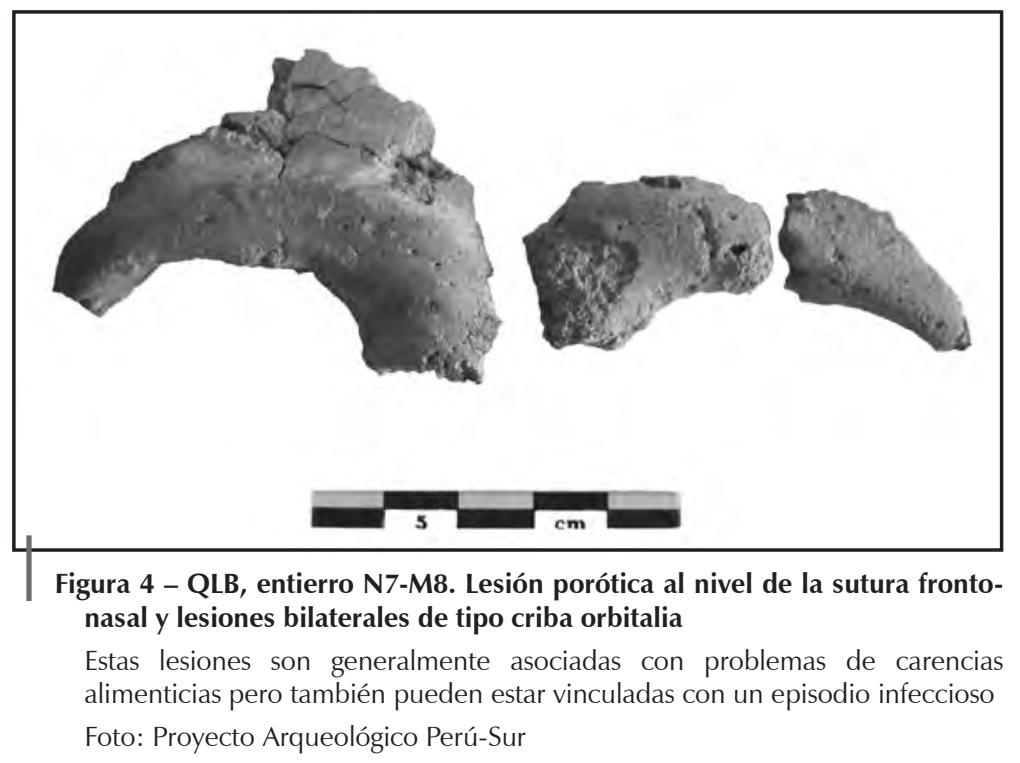

\section{CONCLUSIÓN}

Los restos humanos del Arcaico Temprano son poco numerosos en el área andina central. Las fechas más confiables obtenidas para los escasos entierros hasta la fecha conocidos se muestran, de norte a sur, en el siguiente cuadro. 
Descubrimiento de un entierro del Arcaico Temprano en el sur del Perú

\begin{tabular}{|c|c|}
\hline Sitio & Edad calibrada \\
\hline $\begin{array}{l}\text { La Vegas OGSE-80 (Ecuador): 8250 } \pm 120 \text { (Stothert, 1988: 56- } \\
\text { 57) }\end{array}$ & 9227 cal a.P. \\
\hline Paiján (Perú) : 10200ะ180 (Chauchat, 1992: 178) & 11886 cal a.P. \\
\hline Telarmachay-fase VII (Perú) : 7150ะ90 (Lavallée, 1985 : 57) & $7970 \mathrm{cal} \mathrm{a.P.}$ \\
\hline Acha-2 (Chile) : 8970 255 BP (Muñoz et al., 1993: 28) & 10084 cal a.P. \\
\hline Chinchorro (Chili) : 7810 \pm 180 (Allison et al., 1984: 165) & 8624 cal a.P. \\
\hline
\end{tabular}

Recordemos también la fecha de $9820 \pm 140$ a.P. (calibrada=11249 cal a.P.), obtenida para un entierro descubierto en el área funeraria del Cañón, ubicada a poca distancia de la Quebrada de los Burros y muy probablemente asociada al campamento QLB.

En lo que se refiere al entierro QLB-M8, nivel N7, aquí presentado, si bien es demasiado temprano para proponer cualquiera afiliación morfogenética, su edad radiocarbónica — aproximadamente 9500 a.P.— lo ubica entre los más antiguos restos humanos conocidos en el área andina.

\section{Referencias citadas}

ALLISON, M. J., FOCACCI, G., ARRIAZA, B., STANDEN, V., RIVERA, M. \& LOWENSTEIN, J. M., 1984 - Chinchorro, momias de preparación complicada : métodos de momificación. Chungará, 13: 155-173; Arica: Universidad de Tarapacá.

CHAUCHAT, C., 1992 - Préhistoire de la côte nord du Pérou. Le Paijanien de Cupisnique, 391 pp.; París: CNRS Éditions.

FAIRBANKS, R. G. et al., 2005 - Radiocarbon calibration curve spanning 0 to 50,000 years $\mathrm{BP}$ based on paired ${ }^{230} \mathrm{Th} /{ }^{234} \mathrm{U} /{ }^{238} \mathrm{U}$ and ${ }^{14} \mathrm{C}$ dates on pristine corals. Quaternary Science Reviews, 24: 1781-1796.

LAVALLÉE, D. (ed.), 1985 - Telarmachay. Chasseurs et pasteurs préhistoriques des Andes, 2 vols., 461 pp.; París: Éd. Recherches sur les Civilisations.

LAVALLÉE, D., 2003 - The First Peopling of the South Pacific American Coast during the Pleistoce/Holocene Transition. A Case Study : The Prehistoric Campsite of Quebrada de los Burros (Tacna, Peru). In: Where the South Winds Blows. Ancient Evidence of Paleo South Americans (L. Miotti, M. Salemme \& N. Flegenheimer, eds.): 17-20; Texas: Center for the Study of the First Americans.

LAVALLÉE, D., BÉAREZ, P., CHEVALIER, A., JULIEN, M., USSELMANN, P. \& FONTUGNE, M., 1999 - Paleoambiente y ocupación prehistórica del litoral extremo-sur del Perú. Las ocupaciones del Arcaico en la Quebrada de los Burros y alrededores (Tacna, Perú). Boletin de Arqueología PUCP, 3: 393-416; Lima.

LAVALLÉE, D. \& JULIEN, M., 2001 - Les pêcheurs préhistoriques du Pérou. Pour la Science, 2687: 68-75. 
LAVALLÉE, D. \& JULIEN, M., 2008 - Premiers pêcheurs du littoral pacifique sud-américain. Les Nouvelles de l'archéologie, 111-112: 11-16.

LAVALLÉE, D., JULIEN, M., BÉAREZ, P., USSELMANN, P., FONTUGNE, M. \& BOLAÑOS, A., 1999 - Pescadores-recolectores arcaicos del extremo-sur peruano. Excavaciones en la Quebrada de los Burros (Tacna, Perú). Bulletin de I'Institut Français d'Études Andines, 28 (1): 13-52.

LEGENT, F., 2003 - ORL : Pathologie cervico-faciale, 361 pp.; París: Elsevier Masson.

MUÑOZ OVALLE, I., ARRIAZA, B. \& AUFDERHEIDE, A., 1993 - Acha-2 y los orígenes del poblamiento humano en Arica, 169 pp.; Arica: Universidad de Tarapacá.

STOTHERT, K. E., 1988 - La Prehistoria Temprana de la Peninsula de Santa Elena, Ecuador: Cultura Las Vegas; Guayaquil: Miscelánea Antropológica Ecuatoriana. Serie monográfica 10, Museos del Banco Central del Ecuador. 